\title{
Universal health coverage from multiple perspectives: a synthesis of conceptual literature and global debates
}

Gilbert Abotisem Abiiro ${ }^{1,2^{*}}$ and Manuela De Allegri ${ }^{1}$

\begin{abstract}
Background: There is an emerging global consensus on the importance of universal health coverage (UHC), but no unanimity on the conceptual definition and scope of UHC, whether UHC is achievable or not, how to move towards it, common indicators for measuring its progress, and its long-term sustainability. This has resulted in various interpretations of the concept, emanating from different disciplinary perspectives. This paper discusses the various dimensions of UHC emerging from these interpretations and argues for the need to pay attention to the complex interactions across the various components of a health system in the pursuit of UHC as a legal human rights issue.

Discussion: The literature presents UHC as a multi-dimensional concept, operationalized in terms of universal population coverage, universal financial protection, and universal access to quality health care, anchored on the basis of health care as an international legal obligation grounded in international human rights laws. As a legal concept, UHC implies the existence of a legal framework that mandates national governments to provide health care to all residents while compelling the international community to support poor nations in implementing this right. As a humanitarian social concept, UHC aims at achieving universal population coverage by enrolling all residents into health-related social security systems and securing equitable entitlements to the benefits from the health system for all. As a health economics concept, UHC guarantees financial protection by providing a shield against the catastrophic and impoverishing consequences of out-of-pocket expenditure, through the implementation of pooled prepaid financing systems. As a public health concept, UHC has attracted several controversies regarding which services should be covered: comprehensive services vs. minimum basic package, and priority disease-specific interventions vs. primary health care.

Summary: As a multi-dimensional concept, grounded in international human rights laws, the move towards UHC in LMICs requires all states to effectively recognize the right to health in their national constitutions. It also requires a human rights-focused integrated approach to health service delivery that recognizes the health system as a complex phenomenon with interlinked functional units whose effective interaction are essential to reach the equilibrium called UHC.
\end{abstract}

Keywords: Universal health coverage, Multi-dimensional concept, Rights-based, Population coverage, Financial protection, Access to health services, Health system, Conceptual literature, Global debates

\footnotetext{
*Correspondence: gilbiiro@yahoo.com

${ }^{1}$ Institute of Public Health, Medical Faculty, University of Heidelberg,

Heidelberg, Germany

${ }^{2}$ Department of Planning and Management, Faculty of Planning and Land

Management, University for Development Studies, University Post Box 3, Wa,

Upper West Region, Ghana
}

\section{Biomed Central}

(C) 2015 Abiiro and De Allegri. This is an Open Access article distributed under the terms of the Creative Commons Attribution License (http://creativecommons.org/licenses/by/4.0), which permits unrestricted use, distribution, and reproduction in any medium, provided the original work is properly credited. The Creative Commons Public Domain Dedication waiver (http:// creativecommons.org/publicdomain/zero/1.0/) applies to the data made available in this article, unless otherwise stated. 


\section{Background}

Universal health coverage (UHC) has been acknowledged as a priority goal of every health system [1-5]. The importance of this goal is reflected in the consistent calls by the World Health Organization (WHO) for its member states to implement pooled prepaid health care financing systems that promote access to quality health care and provide households with the needed protection from the catastrophic consequences of out-of-pocket (OOP) health-related payments [2, 6-8]. This call has also been endorsed by the United Nations [5].

In the existing literature, different conceptual terminology, such as universal health care [9], universal health care coverage $[10,11]$, universal health system, universal health coverage, or simply universal coverage, have been used to refer to basically the same concept $[9,12-14]$. Stuckler et al. [15] noted that "universal health care" is often used to describe health care reforms in high income countries while "universal health coverage" is associated with health system reforms within low- and middle-income countries (LMICs). Given that the poor, marginalized and most vulnerable populations mostly reside in LMICs, this paper places relatively high emphasis on such settings. Hence, we adopt the term universal health coverage (UHC) [2] throughout the paper.

It is argued that health system reforms aimed at UHC can be traced back to the emergence of organized health care in the 19th century, in response to labor agitations calling for the implementation of social security systems [16-18]. This phenomenon first started in Germany under the leadership of Otto von Bismarck, and later spread throughout other parts of Europe such as Britain, France and Sweden [16-18]. Later in 1948, the concept of UHC was implicitly enshrined in the WHO constitution which recognized that "the enjoyment of the highest attainable standard of health is one of the fundamental rights of every human being without distinction of race, religion, and political belief, economic or social condition" [19]. This fundamental human right was reaffirmed in the "Health for all" declaration of the Alma Ata conference on primary health care in 1978 [20].

In 2005, the concept of UHC was once again acknowledged and for the first time explicitly endorsed by the World Health Assembly (WHA) as the goal of sustainable health care financing [6]. The World Health Assembly resolution (WHA58.33) explicitly called for the implementation of health care financing systems centered on prepaid and pooling mechanisms aimed at achieving UHC [6]. Based on this Resolution, WHO defined UHC as "access to key promotive, preventive, curative and rehabilitative health interventions for all at an affordable cost, thereby achieving equity in access" [6]. The 2008 World Health Report reemphasized prepayment and pooling systems as essential instruments for UHC by categorically stating that UHC entails "pooling pre-paid contributions collected on the basis of ability to pay, and using these funds to ensure that services are available, accessible and produce quality care for those who need them, without exposing them to the risk of catastrophic expenditures" [7]. In 2010, the World Health Report, further stressed the role of health system financing for UHC by arguing that "countries must raise sufficient funds, reduce the reliance on direct payments to finance services, and improve efficiency and equity" [2]. The concept of UHC as reflected in these WHO reports seems to be focused more on improving the health care financing function of a health system. The 2013 World Health Report built on prior work resulting in a call for research evidence to facilitate the transition of countries towards UHC [8]. The United Nations, the World Bank, the Gates Foundation, Oxfam, United States Agency for International Development (USAID), the International Labour Organization, United Nations Children's Fund (UNICEF), Rockefeller Foundation, Results for Development Institute, the Joint Learning Network, among other international and regional development organizations have also in various ways recently endorsed and promoted the move towards UHC [5, 21-25]. Considering the key role of the $\mathrm{WHO}$ and these other global actors in shaping the health policy debate at the global level, this recent history demonstrates a consistent and increasing international interest in the concept and debates surrounding UHC $[2,26]$.

To date, the literature continues to present a clear consensus on the importance of UHC [23, 27-29]. UHC was described by the Director General of WHO as "the single most powerful concept that public health has to offer" [30]. Its potential to improve the health of the population, especially for the poor, has been demonstrated [31, 32]. It is viewed as the phenomenon that will result in the third global transition and hence greatly influence the (re-) organization and financing of global health systems [29]. As an essential catalyst for poverty reduction and economic growth [14, 33, 34], UHC is regarded as a prerequisite for sustainable development [35]. It has therefore been advocated for as an important health goal in the post-2015 global development agenda [35-40]. The Lancet Commission on Investing in Health reports that this goal can be progressively attained by 2035 [34].

Despite the global consensus on its importance, consensus on the conceptual definition, meaning, and scope of UHC are still missing [12, 26, 41]. Likewise, no consensus exists on whether UHC is achievable or not; on how to move towards it [3, 22, 42, 43]; on common indicators for measuring progress towards it [13, 24, 28, 29, 44]; and on its long-term sustainability [27]. The absence of a clear consensus on the conceptual definition of UHC has resulted in various interpretations of the concept, emanating from different disciplinary perspectives. These different interpretations reveal distinct, but interlinked dimensions of 
UHC [2]. This paper seeks to explore these various interpretations and representations of the concept of UHC from a multidimensional perspective and to discuss the various dimensions of UHC emerging from these interpretations. The arguments presented in this paper are based on a synthesis of the literature emerging from recent global debates on UHC. We adapted the WHO framework [2] to guide the presentation of our synthesis of the conceptual debates currently being advanced in the literature. Inspired by the WHO framework, our conceptual reasoning is that advancing UHC requires a healthy interaction across the three coverage dimensions: population coverage, financial protection and access to health services, held together by the view of health as a legal human right.

\section{Discussions}

\section{Universal health coverage as a legal right to health}

A group of scholars, building their opinions from a legal and human rights perspective, enshrined in various international covenants and treaties [45-49], argue that the concept of UHC implies the existence of a legal framework to ensure that every resident gets access to affordable health care $[15,50,51]$. This portrays UHC as a reformulation of the "health for all" goal of the Alma Ata Declaration [15, 22, 52-54]. The view of UHC as a legal obligation imposed on all states that ratified the convention on the right to health [45], implies that UHC calls for all States to create legal entitlements to health care for all their residents $[50,55,56]$, thereby placing the responsibility for the delivery of UHC on national governments [5, $17,57]$. To guarantee a comprehensive right to health, the legal obligation of the state needs to reach beyond mere health service provision to include deliberate efforts to advance improvements in structures which are recognized to act as important social determinants of health such as, education, housing, sanitation and portable water as well as equitable gender and power relations [58-60]. The goal of UHC and the responsibility of moving towards it, therefore, need to be mandated by national laws $[4,61,62]$. Backman et al. [63] report that only 56 states have constitutional provisions that legally recognize the right to health and argue that even within these states, much work is still needed to ensure that this right is guaranteed in actual practice for all. Kingston et al. [55] also argue that even the state-centered view of the right to health is based on a false assumption that all people have legal nationalities. They insist that this false assumption is the cause for the medical exclusion of some migrants, especially illegal immigrants, from accessing institutionalized health care within their countries of residence. This situation is even more serious in LIMCs, where states find it difficult to raise sufficient revenues to finance health care for their legal citizenry. The vague definition of the right to health for nonnationals premised on the individual state's economic ability and willingness to guarantee it [46], is therefore a potential recipe for social exclusion on the basis of nationality. Current debates on UHC therefore need to seriously reflect on ways by which the rights of stateless individuals to health care can also be guaranteed within the framework of UHC.

Acknowledging financial constraints to enforcing the right to health within poor-resource settings, some scholars explicitly call for international assistance for health as a way of strengthening the right to health component of UHC $[62,64]$. This, they argue, can be implemented through the establishment of a global fund to finance UHC [65] thereby presenting health as a global public good [66]. The notion of creating a common fund for UHC also recognizes the transnational nature of emerging global health problems and the inherent global interdependency needed to deal with such problems [67]. The possibility of funding global efforts towards UHC from this global fund is being explored. Initial results reveal conflicting expectations and interests between the potential donors/financiers and beneficiary countries [65]. The rights-based arguments for UHC therefore suggest a shift on the ethical spectrum of international assistance for health, from the concept of international health, where international assistance for health is viewed as a form of charity, towards that of global health [62, 67-69] which is driven by the cosmopolitan ethical preposition that states should assist each other on the basis of humanitarian responsibility [68, 69] and solidarity [67]. This cosmopolitan ethical view has the potential of facilitating efforts at raising more international assistance to facilitate UHC within its broader dimensions currently being advanced by WHO and other global experts.

\section{Population coverage as a dimension of universal health coverage}

Another group of scholars [22, 61], also supportive of the rights-based perspective, argue that UHC implies "equal or same entitlements" to the benefits of a health system. This reflects the notion of universal enrollment into healthrelated social security or risk protection systems $[17,70]$ or population coverage under public health financing systems [2]. This notion therefore puts people (population) at the center of UHC [71]. Universal population coverage is to be understood in relation to the tenets of the right to health [45] as the absence of systemic exclusion of certain population groups (especially the poor and vulnerable) from the coverage of public prepaid funds and the ability of all residents to enjoy the same entitlements to the benefits of such public funding, irrespective of their nationality, race, sexual orientation, gender, political affiliations, socio-economic status or geographic locations [2, 12, 22, 53, 55, 61, 72-74].

To distinguish between aggregate and equity-based measures of population coverage, both WHO \& the World Bank [24] have defined population coverage along two dimensions. Thus; achieving a $100 \%$ coverage of the total 
population as an aggregate measure, or ensuring a relatively good proportion of coverage of the poorest $40 \%$ compared to the rest of the population as an equity-based measure [24]. The overall notion of equity, defined as progressive income-rated contributions to health financing and needbased entitlements to health services, is embedded in almost all conceptual definitions of universal population coverage [2, 4, 75-77]. Implicit in the notion of equity is the concept of income and risk cross-subsidization [78], whereby the rich cross-subsidize the poor, whilst the healthy cross-subsidize the sick [61]. Notwithstanding this, other scholars have warned that universal population coverage, although desirable, must be carefully pursued to avoid creating a situation of which official entitlements will be offered to all people yet the existing health system may not have sufficient capacity to deliver quality health care for all the population $[79,80]$. This is referred to as adverse incorporation or inclusion [79].

\section{Financial protection as a dimension of universal health coverage}

From the perspective of health economics, UHC is viewed as a means of protection against the economic consequences of ill health [81, 82]. A guaranteed financial protection requires the implementation of a health care financing mechanism that does not require direct (substantial) out-of-pocket (OOP) payments, official or informal, such as user fees, copayments and deductibles, for health care at the point of use $[23,74,81,83]$. This is the reason why the international community has endorsed financing health care from pooled prepaid mechanisms such as tax (general or dedicated) revenue, and contributions from social health insurance (usually for formal sector employees), private health insurance, and micro health insurance as essential pre-requisites for moving towards universal financial protection [6]. The existing literature does not reveal a consensus on the best prepayment mechanism or the right mix of prepayment systems that will guarantee adequate financial protection [22, 84]. A report by Oxfam [22] suggests that within the context of LMICs, different development partners each promote their ideologically favored prepayment mechanisms as a strategy towards achieving UHC. Both the WHO and the academic community, however, recommend that such ideological prescriptions should be abandoned in favor of mixed pooling systems that can coordinate funds from different prepaid sources, in a manner that reflects contextspecific UHC needs $[2,28]$. This recommendation is also rooted in the recognition that no country, not even high income ones, has achieved complete coverage, relying solely on one single financing strategy [4]. Within a mixed pooling system, there is the need to ensure proper monitory of both private and public inputs that go into the financing system.
The WHO recommends two measures for assessing progress towards financial protection: the incidence of catastrophic health care expenditure and the incidence of impoverishment resulting from OOP payments for health care [25]. The proportion of total health care expenditure incurred through OOP payments is normally used as an indicator of financial protection at the national level [2]. WHO recommends a maximum OOP expenditure threshold of $15-20 \%$ of total health care expenditure as a requirement for financial protection [2]. At the household level, a quantitative measure of financial protection is the proportion of households incurring OOP healthcare expenditure exceeding $40 \%$ of their household's nonsubsistence (i.e., non-food) expenditure [85] or $10 \%$ of total household expenditure [86]. It must be noted that direct medical cost of seeking health care is not the only barrier to financial protection. A good estimate of catastrophic health care expenditure must therefore reflect all relevant costs including non-medical costs such as the cost of travelling to a health facility and loss of earnings while being treated among others. These quantitative measures, estimated on the basis of actual health care cost incurred, however, only reflect the true situation of financial risk protection if all those who need care can actually utilize health services [87]. It is argued that, such utilizationfocused quantitative cost estimates are often not able to capture the quantum of needed healthcare that is forgone due to fear of impoverishment associated with utilization [87]. Effective universal financial protection can, therefore, be attained not only if the population does not incur (substantial) OOP payments and critical income losses due to payment for health care, but if there are no fears of and delays in seeking healthcare due to financial reasons, no borrowing and sale of valuable assets to pay for healthcare, and no detentions in hospitals for non-payment of bills [2, 61, $80,86,88-90]$.

\section{Access to services as a dimension of universal health coverage}

From the perspective of public health, it is argued that a UHC package should include a comprehensive spectrum of health services in line with the WHO's conceptualization of $\mathrm{UHC}$ as "access to key promotive, preventive, curative and rehabilitative health interventions ..." [2, 6]. From a feasibility view point, other scholars, however, argue that the focus should be on the provision of a minimum basic package to cover priority health needs for which there are effective lowcost interventions [91]. Some of these scholars insist that this package should include priority services in line with the health-related Millennium Development Goals (MDGs) [14, 24], thereby suggesting a continuous focus on vertical disease-specific interventions. While some of these scholars argue that the expansion and effective implementation of disease-specific interventions, especially those focused on 
prevention, can improve health and reduce health system costs, opponents insist that all disease-specific interventions create fragmentation and undermine broader efforts aimed at system-wide strengthening [92, 93]. The opposing scholars call for a focus on primary health care $[7,15$, 94], to the extent that Yates [74] calls for a clear timetable, proposing 2015 as deadline, for the achievement of universal access to primary health care.

A number of authors further distinguish between official health service coverage, defined in terms of entitlement to services, and actual effective coverage, defined in terms of real access and utilization of health services according to need $[13,44,51]$. It follows that attempts to measure UHC should focus on indicators that measure actual effective service coverage in relation to people's ability to obtain real access to services, without facing barriers on both the demand and the supply side $[13,51,70]$. Real access, is further defined as access in relation to the availability of health services, personnel and facilities; geographical accessibility of health services; acceptability defined in relation to appropriate client-provider interactions, timeliness, appropriateness and quality of services; and affordability in terms of medical and transport costs of services relative to clients' ability-topay [73, 80, 95-106]. A guaranteed sufficient capacity of the local health system, in terms of adequate health infrastructure, qualified human resources, equipment and tools, to deliver quality health care is therefore an essential component of the access dimension of UHC $[2,11,107]$. It is interesting to note that "Availability, Acceptability, Affordability and Quality (AAAQ)" of health services as essential sub-components of real access are directly rooted in the human rights conceptual framework and captured in broader discussions on the right to health $[45,63]$.

\section{Summary}

Considering its interactive facets, it can be concluded that UHC emerges from the literature as a multi-dimensional concept, operationalized in terms of population coverage of health-related social security systems, financial protection, and access to quality health care according to need [17], and pursued within the framework of health care as an international legal obligation grounded in international human rights laws $[45,46,48,49]$. As an essential precondition for moving towards UHC in LMICs, there is therefore the need for all states to abide by the international human rights obligation imposed on them and thereby legally recognize the right to health in their national constitutions. It is only on this basis that the needed national and political commitment can be enhanced for a successful move towards universal population coverage of healthrelated social security systems, financial protection and access to services, which are essential components of a guaranteed comprehensive right to health and hence UHC. $\mathrm{UHC}$ can thus be understood as a broad legal, rights-based, social humanitarian, health economics and public health concept $[15,17,27,42]$. As such, it transcends a mere legal extension of the coverage of prepaid financing systems such as health insurance or tax-based systems to all residents, to ensuring that other financial and health system bottlenecks are removed to enhance effective financial protection and equitable access to services for all. As an overall health system strengthening tool, UHC can only be achieved through a human rights-focused integrated approach that recognizes the health system as a complex phenomenon with interlinked functional units whose effective interaractions are essential to reach the equilibrium called UHC. It follows that in LMICs, interventions aimed at strengthening health systems need to attract as much attention and funding as currently being deployed towards disease-specific interventions within the framework of the MDGs. Such an action has the capability of improving local service delivery capacity and hence of building resilient and responsive health systems to facilitate the move towards UHC. The move towards UHC should therefore be conceptualized as a continuous process of identifying gaps in the various interactive UHC dimensions, and designing contextspecific strategies to address these gaps in accordance with the international legal obligations imposed on states by international agreements on the right to health. As a global issue, international assistance based on the principle of global solidarity is indispensable in the move towards UHC in LMICs.

\section{Abbreviations}

AAAQ: Availability, Acceptability, Affordability, Quality; LMICs: Low - and Middle-Income Countries; MDGs: Millennium Development Goals; OOP: Outof-pocket; UHC: Universal Health coverage; UNICEF: United Nations Children's Fund; USAID: United States Agency for International Development; WHA: World Health Assembly; WHO: World Health Organization.

\section{Competing interests}

The authors declare that they have no competing interests.

\section{Authors' contributions}

GAA conceptualized and designed the study, undertook the literature search, data extraction and analysis, and drafted the paper. MDA supported the conceptualization and design of the study and paper drafting, and critically reviewed the drafts and contributed to its finalization. Both authors read and approved the final manuscript.

\section{Acknowledgement}

GAA was funded by a scientific contract from the Institute of Public Health, University of Heidelberg, Germany, and a senior research assistant contract from the University for Development Studies, Ghana. MDA is fully funded by a core position in the Medical Faculty of the University of Heidelberg, Germany.

Received: 15 January 2015 Accepted: 29 June 2015

Published online: 04 July 2015

\section{References}

1. Garrett L, Chowdhury AMR, Pablos-Méndez A. All for universal health coverage. Lancet. 2009;374:1294-9.

2. WHO. The World Health Report 2010 - Health Systems Financing: the path to universal coverage. Geneva: World Health Organization; 2010. 
3. Mills A, Ally M, Goudge J, Gyapong J, Mtei G. Progress towards universal coverage: the health systems of Ghana, South Africa and Tanzania. Health Policy Plan. 2012;27 suppl 1:14-12.

4. Kutzin J. Health financing for universal coverage and health system performance: concepts and implications for policy. Bull World Health Organ. 2013;91:602-11.

5. United Nations' General Assembly. Global Health and Foreign policy. Agenda item 123. The Sixty-seventh session (A/67/L.36). New York: United Nations; 2012.

6. World Health Organization. Sustainable health financing, universal coverage and social health insurance. Geneva: World Health Organization; 2005.

7. WHO. World Health Report 2008 - primary health care - now more than ever. Geneva: World Health Organization; 2008

8. WHO. WHO | World Health Report 2013: research for universal health coverage. Genena: World Health Organization; 2013.

9. Reddy KS, Patel V, Jha P, Paul VK, Kumar AKS, Dandona L. Towards achievement of universal health care in India by 2020. A call to action. Lancet. 2011;377:760-8.

10. Gorin S. Universal health care coverage in the United States: Barriers, prospects, and implications. Health Soc Work. 1997;22:223-30.

11. Collet T-H, Salamin S, Zimmerli L, Kerr EA, Clair C, Picard-Kossovsky M, et al. The quality of primary care in a country with universal health care coverage. J Gen Intern Med. 2011;26:724-30.

12. O'Connell T, Rasanathan K, Chopra M. What does universal health coverage mean? Lancet. 2013;6736:13-5.

13. de Noronha JC. Universal health coverage: how to mix concepts, confuse objectives, and abandon principles. Cad Saúde Pública. 2013;29:847-9.

14. Kieny M-P, Evans DB. Universal health coverage. East Mediterr Health J. 2013;19:305-6.

15. Stuckler D, Feigl AB, Basu S, McKee M. The political economy of universal health coverage. In: Background paper for the global symposium on health systems research. Geneva: World Health Organization; 2010.

16. Bärnighausen T, Sauerborn R. One hundred and eighteen years of the German health insurance system. Are there any lessons for middle-and low-income countries. Soc Sci Med. 2002;54:1559-87.

17. Savedoff W, de Ferranti D, Smith A, Fan V. Political and economic aspects of the transition to universal health coverage. Lancet. 2012;380:924-32.

18. McKee M, Balabanova D, Basu S, Ricciardi W, Stuckler D. Universal health coverage: a quest for all countries but under threat in some. Value Health. 2013;16(1, Supplement):S39-45.

19. WHO. Constitution of the World Health Organization. Geneva: World Health Organisation; 1948

20. Declaration of Alma-Ata. International Conference on Primary Health Care, Al ma-Ata, USSR, 6-12 September 1978.http://www.euro.who.int/_data/ assets/pdf_file/0009/113877/E93944.pdf. Accessed 4 May, 2015.

21. Bristol N. Global action towards Universal health coverage: a report for the CSIS Global Health Policy Center. Washington DC: Centre for strategic and International Studies; 2014.

22. Oxfam. Universal Health Coverage: Why health insurance schemes are leaving the poor behind. Oxford: Oxfam International; 2013.

23. World Bank WHO. WHO/World Bank Ministerial-level Meeting on Universal Health Coverage 18-19 February 2013. Geneva: World Health Organization's headquarters; 2013.

24. WHO, World Bank. Monitoring Progress towards Universal Health Coverage at Country and Global Levels: A Framework. Joint WHO/World Bank Group Discussion Paper. Geneva: World Health Organization; 2013.

25. World Bank, WHO. Towards Universal Health Coverage by 2030. Washington DC: World Bank Group; 2014.

26. Latko B, Temporão JG, Frenk J, Evans TG, Chen LC, Pablos-Mendez A, et al. The growing movement for universal health coverage. Lancet. 2011;377:2161-3.

27. Borgonovi E, Compagni A. Sustaining universal health coverage: the interaction of social, political, and economic sustainability. Value Health. 2013;16(1, Supplement):S34-8.

28. Kutzin J. Anything goes on the path to universal health coverage? No. Bull World Health Organ. 2012;90:867-8.

29. Rodin J, de Ferranti D. Universal health coverage. The third global health transition? Lancet. 2012;380:861-2.

30. Chan M. Best days for public health are ahead of us, says WHO Director-General. Geneva, Switzerland: Address to the 65th World Health Assembly; 2012.
31. Lee Y-C, Huang Y-T, Tsai Y-W, Huang S-M, Kuo KN, McKee M, et al. The impact of universal National Health Insurance on population health: the experience of Taiwan. BMC Health Serv Res. 2010;10:225.

32. Moreno-Serra R, Smith PC. Does progress towards universal health coverage improve population health? Lancet. 2012;380:917-23.

33. The World Bank. World Development Report 1993. Investing in Health. New York: Oxford University Press; 1993.

34. Jamison DT, Summers LH, Alleyne G, Arrow KJ, Berkley S, Binagwaho A, et al. Global health 2035: a world converging within a generation. Lancet. 2013;382:1898-955.

35. Evans DB, Marten R, Etienne C. Universal health coverage is a development issue. Lancet. 2012;380:864-5.

36. D'Ambruoso L. Global health post-2015: the case for universal health equity. Global Health Action. 2013;6:19661.

37. Sheikh M, Cometto G, Duvivier R. Universal health coverage and the post 2015 agenda. Lancet. 2013;381:725-6.

38. United Nations. Adopting consensus text, General Assembly encourages member states to plan, pursue transition of National Health Care Systems towards Universal Coverage. In: Sixty-seventh General Assembly Plenary 53rd Meeting (AM). New York: Department of Public Information . News and Media Division; 2012.

39. Vega J. Universal health coverage. The post-2015 development agenda. Lancet. 2013:381:179-80.

40. Victora C, Saracci R, Olsen J. Universal health coverage and the post-2015 agenda. Lancet. 2013;381:726.

41. Sengupta M. Universal Health Coverage: Beyond rhetoric. In: McDonald DA, Ruiters G, editors. Municipal Services Project, Occasional Paper No 20 November 2013. http://www.alames.org/documentos/uhcamit.pdf. Accessed 14 May, 2015.

42. Holmes D. Margaret Chan: committed to universal health coverage. Lancet. 2012;380:879.

43. Horton R, Das P. Universal health coverage: not why, what, or when - but how? Lancet. 2014;384:2101.

44. Lagomarsino G, Garabrant A, Adyas A, Muga R, Otoo N. Moving towards universal health coverage: health insurance reforms in nine developing countries in Africa and Asia. Lancet. 2012;380:933-43.

45. Office of the United Nations High Commissioner for Human Rights, WHO. The Right to Health: Joint Fact Sheet WHO/OHCHR/323. Geneva: World Health Organization; 2007.

46. United Nations' General Assemby. International Covenant on Economic, Social and Cultural Rights: Adopted and opened for signature, ratification and accession by General Assembly resolution 2200A (XXI) of 16 December 1966 entry into force 3 January 1976, in accordance with article 27. New York: United Nations; 1966.

47. Young S, The U.S. Fund for UNICEF Education Department. The United Nations Convention on the Rights of the Child: An Introduction -A Middle School Unit (Grades 6-8). U.S. Malawi: Fund for UNICEF/Mia Brandt; 2006.

48. United Nations. Convention on the Rights of Persons with Disabilities. New York: United Nations; 2006

49. United Nations General Assemby. Convention on the Elimination of Al Forms of Discrimination against Women. New York: United Nations; 1979.

50. Bárcena A. Health protection as a citizen's right. Lancet. 2014;6736:61771-2.

51. Scheil-Adlung X, Bonnet F. Beyond legal coverage: assessing the performance of social health protection. Int Soc Secur Rev. 2011;64:21-38.

52. Forman L, Ooms G, Chapman A, Friedman E, Waris A, Lamprea E, et al. What could a strengthened right to health bring to the post-2015 health development agenda?: interrogating the role of the minimum core concept in advancing essential global health needs. BMC Int Health Hum Rights. 2013;13:48.

53. Fried ST, Khurshid A, Tarlton D, Webb D, Gloss S, Paz C, et al. Universal health coverage: necessary but not sufficient. Reprod Health Matters. 2013;21:50-60.

54. Hammonds R, Ooms G. The emergence of a global right to health norm the unresolved case of universal access to quality emergency obstetric care. BMC Int Health Hum Rights. 2014;14:4.

55. Kingston LN, Cohen EF, Morley CP. Debate: limitations on universality: the "right to health" and the necessity of legal nationality. BMC Int Health Hum Rights. 2010;10:11.

56. Yamin AE, Frisancho A. Human-rights-based approaches to health in Latin America. Lancet. 2014;6736(14):61280.

57. Rosen G. A History of Public Health. Maryland: John Hopkins University Press; 1993. 
58. Wilkinson R, Marmot M. Social determinants of health. The solid facts. Copenhagen: World Health Organization; 1998.

59. Marmot M, Wilkinson R. Social determinants of health. New York: Oxford University Press; 2005.

60. WHO. Social determinants of health: report by the Secretariat EB132/14. Geneva: World Health Organization; 2012.

61. McIntyre D. Health service financing for universal coverage in east and southern Africa, EQUINET Discussion Paper 95. Harare: Regional Network for Equity in Health in East and Southern Africa (EQUINET); 2012.

62. Ooms G. From international health to global health: how to foster a better dialogue between empirical and normative disciplines. BMC Int Health Hum Rights. 2014; 14:36.

63. Backman $G$, Hunt $P$, Khosla $R$, Jaramillo-Strouss $C$, Fikre BM, Rumble $C$, et al. Health systems and the right to health: an assessment of 194 countries. Lancet. 2008;372:2047-85.

64. Ooms $G$, Latif LA, Waris A, Brolan CE, Hammonds R, Friedman EA, et al. Is universal health coverage the practical expression of the right to health care? BMC Int Health Hum Rights. 2014; 14:3.

65. Ooms G, Hammonds R. Financing Global Health Through a Global Fund for Health? Working Group on Financing | PAPER 4. London: CHATHAM HOUSE (The Royal Institute of International Affairs); 2014

66. Chen LC, Evans T, Cash R. Health as a global public good. In: Kaul I, Stern M, Grunberg I, editors. Global public goods: international cooperation in the 21st century. New York: Oxford University Press; 1999. p. 284-304.

67. Frenk J, Gómez-Dantés O, Moon S. From sovereignty to solidarity: a renewed concept of global health for an era of complex interdependence. Lancet. 2014:383:94-7.

68. Stuckler D, McKee M. Five metaphors about global-health policy. Lancet. 2008; $372: 95-7$

69. Lencucha R. Cosmopolitanism and foreign policy for health: ethics for and beyond the state. BMC Int Health Hum Rights. 2013;13:29.

70. Knaul FM, González-Pier E, Gómez-Dantés O, García-Junco D, ArreolaOrnelas $\mathrm{H}$, Barraza-Lloréns $\mathrm{M}$, et al. The quest for universal health coverage: achieving social protection for all in Mexico. Lancet. 2012;380:1259-79.

71. The Lancet. Universal health coverage post-2015: putting people first. Lancet. 2014:384:2083.

72. Allotey $P$, Verghis $S$, Alvarez-Castillo F, Reidpath DD. Vulnerability, equity and universal coverage - a concept note. BMC Public Health. 2012;12 Suppl $1: \mathrm{S} 2$.

73. Ravindran TS. Universal access: making health systems work for women. BMC Public Health. 2012;12 Suppl 1:S4.

74. Yates R. Universal health care and the removal of user fees. Lancet. 2009:373:2078-81.

75. McIntyre D. What healthcare financing changes are needed to reach universal coverage in South Africa? SAMJ: S Afr Med J. 2012;102:489-90.

76. Mills A, Ataguba JE, Akazili J, Borghi J, Garshong B, Makawia S, et al. Equity in financing and use of health care in Ghana, South Africa, and Tanzania: implications for paths to universal coverage. Lancet. 2012;380:126-33.

77. Rodney AM, Hill PS. Achieving equity within universal health coverage: a narrative review of progress and resources for measuring success. Int J Equity Health. 2014;13:1-72.

78. Goudge J, Akazili J, Ataguba J, Kuwawenaruwa A, Borghi J, Harris B, et al. Social solidarity and willingness to tolerate risk- and income-related cross-subsidies within health insurance: experiences from Ghana, Tanzania and South Africa. Health Policy Plan. 2012;27 suppl 1:155-63.

79. Hickey S, Du Toit A. Adverse incorporation, social exclusion and chronic poverty, CPRC Working Paper 81. Chronic Poverty Research Centre: Manchester, UK; 2007.

80. Abiiro GA, Mbera GB, De Allegri M. Gaps in universal health coverage in Malawi: a qualitative study in rural communities. BMC Health Serv Res. 2014;14:234

81. Palmer N, Mueller DH, Gilson L, Mills A, Haines A. Health financing to promote access in low income settings-how much do we know? Lancet. 2004:364:1365-70.

82. Xu K, Evans DB, Kawabata K, Zeramdini R, Klavus J, Murray CJL. Household catastrophic health expenditure. A multicountry analysis. Lancet. 2003;362:111-7.

83. Mclntyre D, Ranson MK, Aulakh BK, Honda A. Promoting universal financial protection: evidence from seven low-and middle-income countries on factors facilitating or hindering progress. Health Res Policy Syst. 2013;11:36.
84. Kutzin J, Ibraimova A, Jakab M, O'Dougherty S. Bismarck meets Beveridge on the Silk Road: coordinating funding sources to create a universal health financing system in Kyrgyzstan. Bull World Health Organ. 2009;87:549-54.

85. Xu K, Evans DB, Carrin G, Aguilar-Rivera AM, Musgrove P, Evans T. Protecting households from catastrophic health spending. Health Affair. 2007;26:972-83.

86. Cleary S, Birch S, Chimbindi N, Silal S, Mclntyre D. Investigating the affordability of key health services in South Africa. Soc Sci Med. 2013;80:37-46.

87. Moreno-Serra R, Millett C, Smith PC. Towards improved measurement of financial protection in health. PLoS Med. 2011;8, e1001087.

88. Dekker M, Wilms A. Health insurance and other risk-coping strategies in Uganda. The case of Microcare Insurance Ltd. World Dev. 2009;38:369-78.

89. Kruk ME, Goldmann E, Galea S. Borrowing and selling to pay for health care in low- and middle-income countries. Health Aff. 2009:28:1056-66.

90. Leive A, Xu K. Coping with out-of-pocket health payments: empirical evidence from 15 African countries. Bull World Health Organ. 2008:86:849-56.

91. Sachs JD. Achieving universal health coverage in low-income settings. Lancet. 2012;380:944-7.

92. Adam T, Hsu J, de Savigny D, Lavis JN, Røttingen J-A, Bennett S. Evaluating health systems strengthening interventions in low-income and middleincome countries: are we asking the right questions? Health Policy Plan. 2012;27 suppl 4:iv9-19.

93. Rao KD, Ramani S, Hazarika I, George S. When do vertical programmes strengthen health systems? A comparative assessment of disease-specific interventions in India. Health Policy Plan. 2014;29:495-505.

94. Sustainable Development Solutions Network. Health in the framework of development: Technical Report for the Post-2015 Development Agenda. New York: Sustainable Development Solutions Network: Global Inititative for the United Nation; 2014

95. Aday $L A$, Andersen R. A framework for the study of access to medical care. Health Serv Res. 1974:9:208-20.

96. Arnold C, Theede J, Gagnon A. A qualitative exploration of access to urban migrant healthcare in Nairobi, Kenya. Soc Sci Med. 2014;110:1-9.

97. Dillip A, Alba S, Mshana C, Hetzel MW, Lengeler C, Mayumana I, et al. Acceptability - a neglected dimension of access to health care: findings from a study on childhood convulsions in rural Tanzania. BMC Health Serv Res. 2012;12:113.

98. Ensor T, Cooper S. Overcoming barriers to health service access: influencing the demand side. Health Policy Plan. 2004;19:69-79.

99. Evans DB, Hsu J, Boerma T. Universal health coverage and universal access. Bull World Health Organ. 2013;91:546-546A.

100. Goudge J, Gilson L, Russell S, Gumede T, Mills A. Affordability, availability and acceptability barriers to health care for the chronically ill: longitudinal case studies from South Africa. BMC Health Serv Res. 2009;9:75.

101. Jacobs B, Ir P, Bigdeli M, Annear PL, Damme WV. Addressing access barriers to health services: an analytical framework for selecting appropriate interventions in low-income Asian countries. Health Policy Plan. 2012;27:288-300

102. Macha J, Harris B, Garshong B, Ataguba JE, Akazili J, Kuwawenaruwa A, et al. Factors influencing the burden of health care financing and the distribution of health care benefits in Ghana, Tanzania and South Africa. Health Policy Plan. 2012;27 suppl 1:146-54.

103. Mclntyre D, Thiede M, Birch S. Access as a policy-relevant concept in lowand middle-income countries. Health Econ Policy Law. 2009;4(Pt 2):179-93.

104. O'Donnell O. Access to health care in developing countries: breaking down demand side barriers. Cad Saúde Pública. 2007;23:2820-34.

105. Penchansky R, Thomas JW. The concept of access: definition and relationship to consumer satisfaction. Med Care. 1981;19:127-40.

106. Silal SP, Penn-Kekana L, Harris B, Birch S, Mclntyre D. Exploring inequalities in access to and use of maternal health services in South Africa. BMC Health Serv Res. 2012;12:120.

107. Meessen B, Malanda B. No universal health coverage without strong local health systems. Bull World Health Organ. 2014;92:78-78A. 